\title{
ECONOMIA CRIATIVA NO MERCADO DA MODA E SUA INFLUÊNCIA NO DESENVOLVIMENTO DA INDÚSTRIA TÊXTIL NO NORDESTE
}

Francisco Oliveira da Silva ${ }^{1}$

Altamira Vicente dos Santos ${ }^{2}$

RESUMO: Este trabalho contempla um extrato do trabalho de monografia executado pelo pesquisador, cujo tema foi: "A economia criativa no mercado da moda e sua influência no desenvolvimento da indústria têxtil no Nordeste. O objetivo geral é identificar a influência econômica da economia criativa no mercado da moda no desenvolvimento da indústria têxtil na região nordeste. Especificamente pretendeuse: Contextualizar sobre economia criativa e moda no Brasil; Caracterizar a atuação da economia criativa no mercado da moda na economia brasileira; e explorar a influência da economia criativa na moda, e desenvolvimento da indústria têxtil no Nordeste. Metodologicamente foi feito uma pesquisa de cunho exploratória e análise descritiva com abordagem qualitativa utilizando dados secundários, além de pesquisa bibliográfica e documental, tomando como território o Nordeste e a atuação da economia criativa nas industrias têxtis. Quanto aos métodos de coletas foram utilizados os métodos de pesquisa bibliográfica documental. Viu-se que apesar da inserção da economia criativa em grandes industrias têxtis ser recente, nota-se um aumento considerável do uso de técnicas artesanais populares, como bordados, crochês, dentre outros. Logo, o estudo mostra como o mercado têxtil Nordestino é um dos principais setores responsáveis pela economia da região gerando produto e renda para seus residentes e que apresentando uma modernização tardia, vem crescendo e se inovando em tecnologia, sendo considerada a a segunda região têxtil mais importante do país.

Palavras-Chave: Economia criativa; Indústria têxtil; Região Nordeste.

\section{CREATIVE ECONOMY IN THE FASHION MARKET AND ITS INFLUENCE ON THE DEVELOPMENT OF THE TEXTILE INDUSTRY IN THE NORTHEAST}

\begin{abstract}
This work includes an extract from the monograph work performed by the researcher, whose theme was: "The creative economy in the fashion market and its influence on the development of the textile industry in the Northeast. The general objective is to identify the economic influence of the creative economy in the fashion market in the development of the textile industry in the northeast region. Specifically, it was intended: To contextualize about creative economy and fashion in Brazil; Characterize the performance of the creative economy in the fashion market in the Brazilian economy; and explore the influence of the creative economy on fashion, and

\footnotetext{
${ }^{1}$ Graduado em Ciências Econômicas pela Universidade Regional do Cariri (URCA/ Iguatu).

2 Graduada em Ciências Econômicas (URCA), Mestra em Desenvolvimento Regional e Sustentável (UFCA) e docente do referido curso (URCA/Iguatu).
} 
development of the textile industry in the Northeast. Methodologically, an exploratory research and descriptive analysis was carried out with a qualitative approach using secondary data, in addition to bibliographic and documentary research, taking as territory the Northeast and the performance of the creative economy in the textile industries. As for the collection methods, the methods of documentary bibliographic research were used. It was seen that although the insertion of the creative economy in large textile industries is recent, there was a considerable increase in the use of popular craft techniques, such as embroidery, crochet, among others. Therefore, the study shows how the northeast textile market is one of the main sectors responsible for the economy of the region generating product and income for its residents and that presenting a late modernization, has been growing and innovating in technology, being considered the second most important textile region in the country.

Keywords: Creative economy; Textile industry; Northeast Region.

\section{INTRODUÇÃO}

No Brasil, a economia criativa já é uma realidade que cresce a cada ano. Segundo a Federação das Indústrias do Estado do Rio de Janeiro, a Firjan, este modelo inovador representa $2,6 \%$ do PIB brasileiro. Uma das principais características desta nova economia é a criatividade e isto não pode ser medido industrialmente dentro de antigos métodos de trabalho. Ou seja, a economia criativa é fruto das constantes evoluções e dinamismo do século XXI, sendo aplicado em segmentos onde a criatividade e conhecimento são os valores principais.

Com a forte concorrência no mercado mundial e econômico, surge o conceito de economia criativa, originário a partir da inserção de algumas indústrias, por sua vez inspirado no projeto Creative Nation, da Austrália, de 1994. Entre outros elementos, este defendia a importância do trabalho criativo além de contribuição de renda para a economia do país, usando a seu favor as tecnologias como fortes aliadas da política cultural, dando margem à posterior introdução de setores tecnológicos no rol das indústrias criativas. De início foram criados 13 setores de maior potencial, onde a criatividade, então caracterizadas como indústrias criativas, atuam com princípios baseados na criação constante, no desenvolvimento de habilidades e talentos individuais e coletivos (SANTOS, 2016).

No Brasil esse mercado passou a ser mais forte nos anos $2000 \mathrm{com}$ a chegada do porto digital em Recife. Em alguns estados Brasileiros este mercado de economia criativa é ainda mais forte, devido a diversos fatores, um deles o mercado tecnológico mais avançado, e a força de consumo da população sedenta por inovação. A mesma 
aplicada na indústria da moda têxtil se configura como um desafio de estar em constante mudança, se adequando as novas tendências e trazendo novidades (LEVIN, 2017).

Nesse sentido, este estudo toma como território a região Nordeste do Brasil, e busca responder qual a influência econômica da economia criativa no mercado da moda e no desenvolvimento da indústria têxtil na região Nordeste.

Este estudo se justifica na medida em que convém verificar a importância da inclusão da economia criativa no setor da moda e posteriormente como ele se inseriu nos polos têxteis da região Nordeste do Brasil. A economia criativa responde hoje por boa parte da geração de renda e empregos em vários países. Como a lógica dos bens criativos é diferente de outras indústrias, a exemplo da construção ou da alimentação, que seguem um modelo de produção e distribuição mais tradicional, entender como funciona essa estrutura criativa ajuda na hora de criar políticas públicas econômicas e até ambientais, organizar redes de inovação, proteger propriedades intelectuais, além de estimular o mercado em torno delas.

Assim, o estudo tem como objetivo geral identificar a influência econômica da economia criativa no mercado da moda no desenvolvimento da indústria têxtil na região nordeste. Os objetivos específicos são divididos em três: Contextualizar sobre economia criativa e moda no Brasil; Caracterizar a atuação da economia criativa no mercado da moda na economia brasileira; e por fim, explorar a influência da economia criativa na moda, e desenvolvimento da indústria têxtil no Nordeste.

\section{METODOLOGIA}

Quanto a natureza da pesquisa, consistiu em uma pesquisa básica cujos objetivos foram de cunho exploratórios. A abordagem foi qualitativa, por não se preocupar com dados numéricos, mais sim com a compreensão mais profunda dos fatos seja de um grupo social ou uma organização.

Os dados foram secundários, com foco na região Nordeste do Brasil, onde segundos dados, a região possui mais de 49 milhões de habitantes, quase $30 \%$ da população brasileira, sendo a segunda região mais populosa do país (IBGE, 2017). Os sujeitos do estudo foram as indústrias têxteis atuantes na região Nordeste.

Com relação a coleta, se fez uso das pesquisas bibliográfica e documental. Os métodos das coletas bibliográfica e documental serviram para buscar embasamentos 
em livros, artigos e revistas à cerca do mercado criativo da moda que pudessem justificar a inserção da economia criativa nas indústrias têxtil da região Nordeste. A análise realizada foi a descritiva, justificada por descrever os principais dados e observar as situações que levam a novos fatos a partir das coletas.

\section{REFERÊNCIAL TEÓRICO}

Esta seção discorre acerca da economia ligada ao mercado da moda, que é o setor econômico que mais cresce nos últimos anos, por ser um mercado que se utilizada da criatividade e das habilidades dos indivíduos ou grupos se diferenciando assim dos demais mercados. Apresenta-se, ainda, dados do setor de economia criativa relacionada à moda no Brasil, com ênfase na região Nordeste mostrando a ligação de economia criativa com este segmento.

\subsection{ECONOMIA CRIATIVA NO BRASIL}

A economia criativa trabalha com a inovação, com o novo, e quebra as linhas do tradicionalismo. Esse conceito é algo abrangente e ilimitado, tanto para as profissões, quanto para a esfera da produção. Os recursos se renovam e possibilita a multiplicação da produção, parcerias, dentre outros. Então, a criatividade tem toda uma possibilidade de expansão de inventividade, e isso depende da industrialização, capacidade de produção, força de trabalho, fatores de produção, e todos os recursos humanos e naturais disponíveis (CARVALHO; ALVIM, 2011).

O Brasil é um dos países que mais lucraram com a economia criativa nos últimos anos, de acordo com a Secretaria de Economia Criativa criada pelo Decreto 7743, de $1^{\circ}$ de junho de 2012 e vinculada ao Ministério da Cultura considera 20 setores dentro da economia criativa no Brasil, artes cênicas, música, artes visuais, literatura e mercado editorial, audiovisual, animação, games, software aplicado à economia criativa, publicidade, rádio, TV, moda, arquitetura, design, gastronomia, cultura popular, artesanato, entretenimento, eventos e turismo cultural (SANTOS; SILVA, 2010).

Esse mercado passou a ser mais forte no país nos anos 2000 com a criação do porto digital em Recife. Um dos principais empreendimentos do setor no país, onde este mesmo era orientado para o mercado Global, fundado em 2000, o projeto nasceu 
com três empresas e 46 pessoas. Em 2014 eram 230 companhias e 7000 funcionários incluindo multinacionais como Microsoft, IBM e Accenture. No mesmo ano a Fiat Chrysler Automobiles anunciou a instalação de um centro de tecnologia automotiva que teve um investimento de 500 milhões de reais e empregou 1000 pessoas, entre engenheiros, técnicos e outros profissionais (PORTO DIGITAL, 2011).

Mesmo diante a crise de 2008, o Brasil continua a crescer neste ramo da economia em quase todos os setores, sendo o Brasil um país bastante rico em cultura, sua população é uma das que mais consomem neste mercado, dentre eles, rádio, tv e moda até a gastronomia, incluindo a cultura popular como turismos culturais, entre outros. Para os economistas mesmo com a grave crise e o PIB tendo tido uma queda de $3,7 \%$ com a inflação atingindo $10,7 \%$ no ano, a economia criativa estava surfando no maremoto econômico que o país passava. O PIB da indústria criativa brasileira chegou a $R \$ 126$ bilhões no fim de 2013 , o equivalente a $2,6 \%$ do total produzido no país naquele ano. Representa avanço de 69,8\% em dez anos, acima dos 36,4\% registrados pelo PIB nacional no mesmo período de acordo com a Organização das Nações Unidas (ONU, 2013).

O Brasil também conta com diversas empresas que atuam indiretamente na economia criativa, como por exemplo as fábricas de instrumentos musicais que abastecem o 19 núcleo da música ou livrarias que vendem produtos para o mercado editorial essas empresas são vistas como um núcleo de apoio para o mercado criativo, não possuem atuação direta mais colaboram para a infraestrutura adequada para 0 desempenho dessas atividades criativas, como por exemplo uma concessionaria de eletricidade (SANTOS, 2017).

Com essa junção indireta de algumas empresas tanto de pequeno porte como de grande porte o país gerou 683.000 empregos formais, ou seja, o equivalente a 1,82\% dos empregos formais do país no ano de 2006 segundo o ministério do trabalho (ORAIS 2006).

\subsection{ECONOMIA CRIATIVA RELACIONADA A MODA NO BRASIL: DADOS E PERSPECTIVAS}

Muito se tem falado sobre o conceito de economia criativa e moda nos últimos anos principalmente neste atual cenário econômico em que estamos vivendo, chamam-se de nova economia fundamentada em pressupostos da criatividade 
humana além de ser cultural. A mesma está sempre se inovando diferentes nos demais mercados, em especial no setor de moda que mantém uma evolução constante. A busca por produtos que envolvam moda está cada vez maior em todo território, já que as pessoas estão cada vez mais preocupadas com a aparência e com o status que uma boa roupa ou sapato proporciona a sua imagem. E é esse consumo crescente o responsável pela importância do setor criativo de moda para a economia do país (UNCTAD, 2008).

Os primeiros vestígios de moda no Brasil foram ao século XIX por conta da influência da corte portuguesa que estava se instalando no Brasil, Nesta época já se tinha revistas importadas de moda trazidas para o Brasil, também já se começaram a pegar tendências francesas de moda para as ruas do Rio de Janeiro, e também começaram as importações de tecidos vindos dos Estados Unidos (REZENDE, 2010).

Grandes lojas luxuosas começaram a surgir a partir de 1930, estilistas brasileiros começaram a se destacar no mercado, porém, a moda era usada pela elite, os grandes empresários daquela época. No governo de Juscelino Kubitschek começa o incentivo de fazer da moda não só um mercado para elite mais um mercado cultural que só veio a ter mais êxito nos governos progressistas (BENATTI, 2011).

$\mathrm{Na}$ década de 1990 o mercado brasileiro abriu suas portas para o mercado internacional o que causou uma enorme queda aos produtos nacionais principalmente o mercado criativo da 27 moda, lojas nacionais começaram a vender grandes marcas internacionais o que fez com que as nacionais tivessem uma queda significante naquela época. Porém com a estabilização da economia e o fortalecimento do setor, marcas antigas começaram a se estabelecer novamente juntos com novos nomes nacionais, fortalecendo o mercado criativo da moda só que agora com produtos nacionais dando uma identidade mais brasileira.

O mercado de moda no Brasil é bastante qualificado e desenvolvido, existem diversas marcas em todo segmento do mercado, vários polos têxteis e fábricas estão espalhados por todo Brasil representando 13,15\% dos empregos da indústria de transformação e 5,5\% do PIB total brasileiro. Eventos de moda como são Paulo Fashion Week dentre outros que tem dimensão mundial atraindo olhares de todo o mundo para a criatividade brasileira, além da exportação de marcas brasileiras para todo o mundo (REZENDE, 2011).

Além de proporcionar emprego para quase dois milhões de pessoas sejam eles 
diretos ou indiretos sejam em indústrias voltadas para a moda ou em parcerias em redes sociais, a mesma se destaca dentro da economia por ser diversificada e conseguir abranger todas as áreas e públicos ao mesmo tempo. A indústria da moda não se preocupa apenas com a produção em larga escala. Nesse setor, é necessária a busca pela diferenciação de mercado entrar no gosto pessoal de cada público em cada região. Assim, a indústria da moda compete no mercado baseando-se em custos e na gestão de produtos. A demanda por produtos de moda é variável de acordo com diversos fatores que estejam acontecendo naquele momento o que torna a indústria da moda bastante vulnerável no mercado econômico (ABIT, 2013).

Ademais, a moda movimenta não só a economia como também o comportamento. É a indústria, é trade, é a gastronomia, é o design. Tudo se completa com a proposta de movimentar esse mundo da moda (SILVEIRA; CLAÚDIO, 2013).

O Brasil sempre foi considerado um dos maiores consumidores de moda do planeta, porém, passou a ter uma pasta na secretária de cultura a partir dos governos progressistas entre (2002-2010), algo ainda recente. Foi no governo de Luiz Inácio Lula da Silva que se iniciou toda a discussão o que seria o novo plano nacional de cultura e arte no Brasil, onde o mesmo teve a participação da população para a formulação do mesmo. Então algumas ações foram criadas no sentido de articular alguns meios para que o mercado da moda viesse a ter mais espaço no governo e fosse mais vista e compreendia pelo grande público como um setor que vai muito além da produção industrial conhecida tradicionalmente pelo público mais amplo, além da produção industrial tradicional como antes era vista (BORDIEU, 2005, p. 70).

A moda passou a se destacar em todo território passando por todas as classes sociais, sendo vista não só como algo de passarelas mais como um mercado que está inserido no dia a dia de cada indivíduo, seja ele de qualquer classe social, além de passar a ser visto como um ótimo mercado de geração de emprego e renda para população (IARA, 2016).

\subsection{A INDÚSTRIA TÊXTIL NA REGIÃO NORDESTE E SUA LIGAÇÃO COM ECONOMIA CRIATIVA E MODA}

Há questionamentos com relação ao mercado têxtil e moda estarem ligados a esse novo conceito de economia criativa, na medida em que ainda o conceito de economia criativa estar mais voltada para economia cultural, aquela mais popular. 
Porém indústrias têxtis é um mercado que já surgiu desde muitos anos para a criação de fios e vestuários entre outros e vêm se adaptando a estes novos conceitos desde o início dos anos 2000 onde a economia criativa se intensifica no país (ROCHA, 2002).

Nesse sentido, sabe-se que a economia criativa vai muito além, apesar de ser um mercado novo no nosso país ainda pouco explorado, o mercado abrange tudo o que se é criativo, todo trabalho ou indústria que trabalhe com a criação individual ou coletiva dos indivíduos. Assim, o mercado da moda é um dos mais fortes e dinâmicos mercados ligados a economia criativa no Brasil e no mundo e dentro da cadeia produtiva da moda ela está ligada diretamente ao mercado têxtil, ou indústrias têxteis, sendo a região Nordeste uma referência na industrialização do país (ROCHA, 2002).

A indústria da moda é uma das mais dinâmicas e produtivas do mundo. No Brasil, o polo têxtil da região do Agreste - composto por mais de 50 municípios, como Caruaru, Toritama e Santa Cruz do Capibaribe - vem alavancando a produção brasileira, revelando mais um potencial da região (ALBUQUERQUE, 2003).

Para a ABIT associação brasileira da indústria têxtil (2005). O Brasil é o quinto maior produtor têxtil do mundo, e um dos principais motivos é que o país é um dos que mais produzem algodão no mundo sendo o setor de vestuário o segundo maior produtor. É importante ressaltar que São Paulo é o maior produtor de vestuário do mundo o que faz com que o mercado têxtil seja um dos principais seguimentos para a moda e também para a economia brasileira (ABIT, 2005).

Já na região Nordeste o polo mais conhecido da indústria têxtil dentro da moda é na capital do Ceara Fortaleza o polo atua como um dos principais criadores de peças intima e malhas para o Brasil e para o mundo, além das grandes indústrias de confecções de roupas com estampas bem tropicais inspiradas nas praias do Ceará, o que gera uma economia diferente.

Além da industrialização tradicional surge o que chamamos da nova economia criativa uma junção do que já se via na antiga forma da industrialização, porém com essa nova fonte de gerar economia, emprego e renda, as indústrias têxteis tradicionais passaram a lucrar cada vez mais aderindo a essa nova forma de criação, surgindo assim o termo economia criativa ou indústrias criativas (ABIT, 2005).

Ainda o Estado do Ceará, na região Nordeste, atualmente só perde neste ramo de industrialização têxtil, para São Paulo e Santa Catarina sendo assim o terceiro maior estado do Brasil que mais gera renda e emprego com mercado têxtil no País 


\section{(INSTITUTO EUVALDO LODI 2000).}

Além de todo lucro visado e adquirido no Nordeste com as indústrias têxteis que é imensamente importante para a economia da região e do país, mas também entra não somente o lucro mais o desenvolvimento do lado social do mercado o que podemos atribuir a economia criativa. Este lado social tem como objetivo trabalhar as raízes culturais destes estados da região onde sua grande maioria são micro e pequenos empresários que trabalham com confecção do tecido a mão usando toda cultura de seu estado deixando assim o mercado criativo têxtil da moda cada vez mais bonito e fazendo com que essas peças sejam exportadas nacionalmente como também internacionalmente (ROCHA, 2002).

\section{RESULTADOS E DISCUSSÕES}

Esta seção tece a importância de compreender o desenvolvimento do mercado têxtil, como ele engloba o mercado da economia criativa, sendo responsável por uma boa parte do PIB, em especial no Nordeste.

O setor está em constante desenvolvimento formado por grandes estudos de mercado, preparação corte e alinhamento, aliando a economia criativa como uma ferramenta para aumento da produção. No Nordeste, a produção deste setor é composta de uma grande variedade de tipos de produtos destinados a usos especifico (ROCHA \& NUNES, 2006).

As empresas têxteis de moda trabalham das seguintes formas: por pedidos ou coleções, sendo as que trabalham com coleções mais ligadas a economia criativa da moda. Atualmente, grandes marcas internacionais e locais são um fenômeno no quesito uso de técnicas artesanais/ culturais identitárias da região. A critério de exemplo, o Dragão fashion, no Ceará, já apresentou coleções inspiradas em paisagens locais mostrando peças bem típicas do estado. Assim, o mercado está trabalhando toda confecção industrial e englobando cada dia mais o fenômeno que é economia criativa aliada ao local, como crochê, bordados, paisagens, dentre outros. (NUNES, 2001).

Ainda se destacam outros fatores para que este mercado se torne mais bem sucedidos em todo país em relação a sua produção, um dos motivos é a estrutura que o mercado têxtil criativo da moda tem. A sua estrutura industrial é altamente heterogênea, sempre influenciada pelo tipo de produto fabricado, na qual se 
predomina a existência de pequenas unidades de produção, pois o mercado está sempre se renovando com isso não há tanto acumulo de estoque. Por outro lado, há uma elevada competição devida às mudanças da moda que está sempre em transformação a cada estação, e ao ciclo sazonal de produção, principalmente no ramo do vestuário feminino, cuja obsolescência programada do produto contribui para expandir ainda mais o mercado (GOULARTI, 2000).

Ainda é importante frisar que este mercado de moda é o que mais se trabalha com mulheres onde mais da metade de seus costureiros na produção são compostos por mulheres, tanto na parte da indústria como também na produção mais cultural, mais popularmente criativa. Para os empresários, esse maior número de mulheres na indústria têxtil facilita mais o contato com cliente na hora de vender e até mesmo de criar na medida em que as mulheres têm uma maior habilidade com as máquinas o que faz com que esta produção seja feita em menor tempo e em uma ótima qualidade (OLIVEIRA; BIANCO, 2005).

$\mathrm{Na}$ modernidade onde tudo muda a cada momento, onde tudo está em constante modificação no mercado da moda têxtil não é diferente, a evolução da maquinas se fizeram necessárias e a região Nordeste teve que se adaptar as novas mudanças de tecnologias do mercado, pois seus principais concorrentes eram os países asiáticos, que a cada dia vêm se renovando investindo cada vez mais em novas técnicas (ITMA, 2011).

Por exemplo, estudos mostram que o Brasil é um dos países que mais produzem neste segmento peças de boa qualidade, pois os clientes Brasileiros são extremamente exigentes quando se trata de moda têxtil, sua classe artística principalmente. E um dos fatores que diferenciam estas peças dos demais concorrentes é a cultura Brasileira, e em especial a Nordestina (CHARLES, 2011).

E com essa modernização tecnológica e essa inserção da cultura nas criações, os estados Nordestinos passaram a investir não só nas maquinas, mas também na arte, e principalmente na qualificação de seus funcionários que passaram a ter cursos voltados para o mercado para que se adaptassem a era da tecnologia. Os estados vêm investindo pesado em Máquinas bem elaboradas para a arte de tecer, de beneficiar, de fiar e de confeccionar as peças. Estão sendo adequadas à formação de técnicos e de engenheiros preparados para a manufatura de produtos de excelente qualidade que ofereçam grande distinção aos seus compradores. Médias e pequenas 
empresas mais intensivas em arte e principalmente em tecnologia, e com grande capacidade organizacional para atuar em mercados externos irão estar na base da nova estrutura industrial têxtil e de confecção Nordestina (UNCTAD, 2011).

Assim, o Nordeste vem se destacando como uma das regiões que mais exportam produtos têxteis para fora do país, além da região também está importando menos maquinários de exterior, pois está cada vez mais investindo em tecnologias e investindo em pesquisas de campo, pesquisas com clientes para que possam se renovar cada vez mais dentro do mercado (IEMI, 2011).

A intensificação da economia criativa nos anos 2000 dentro do mercado da moda faz com que o mercado têxtil passe a crescer ainda mais em todo o mundo e no Brasil não foi diferente essa nova forma de economia veio a acrescentar e muito no ramo têxtil na região Nordeste, Os estilistas locais passaram a ter mais espaço no mercado, dando um ar mais cultural para as peças produzidas, com isso estes profissionais passaram a serem mais qualificados e a indústria têxtil passou a ser mais organizada e a usar criações com características mais culturais de acordo com a região local (SABEL, 2000).

Dessa forma, o mercado têxtil se renova cada vez mais além da tecnologia das novas maquinas dos profissionais mais qualificados, e um dos pontos mais discutidos nos dias atuais é a inserção da economia criativa nesta junção moda têxtil e confecção, o que podemos chamar de customização, a indústria têxtil Brasileira e Nordestina estão cada vez mais investindo neste segmento, que promete crescer cada vez mais nos anos seguintes, pois, além de dar bons resultados seu custo não é tão alto como o mercado mais tradicional.

\section{CONSIDERAÇÕES FINAIS}

Logo, vê-se que a inserção da economia criativa ao setor têxtil, especificamente na região Nordeste, trouxe grandes benefícios na medida em que as peças ficaram mais características a identidade da sua região o que deu mais brasilidade e fez com que o mercado aumentasse o número de exportações ao exterior, além de estar valorizando e contratando mais pessoas de associações mais populares, como bordadeiras, gerando desenvolvimento e renda local na medida em que desse promove a valorização do artesanato local, fazendo assim do mercado, que antes era 
totalmente elitizado, mais "pop" (termo utilizado para popularizar produtos de artefatos de moda).

Ainda há muito a se fazer para que o mercado têxtil da moda se torne mais ainda inserido no termo de economia criativa. Alguns aspectos ainda precisam ser mudados, principalmente, em investimentos para incorporar mais inspirações nacionais e menos internacionais, e principalmente tornar o mercado mais acessível para que o público brasileiro consuma menos produtos asiáticos e europeus que são os principais concorrentes brasileiros tanto no mercado "pop" como no mercado elitizado.

Logo, nota-se que a economia criativa ligada a moda e a mesma inserida nas indústrias têxteis locais no Nordeste é um forte mecanismo de identidade que atuando neste setor promove a adoção de novas técnicas criativas, emprego, geração de renda, crescimento e desenvolvimento regional.

Complementando, é interessante que este estudo incentive mais pesquisas nesta área, a fim de incentivar mais conhecimento, além de atitudes empresariais e governamentais para o desenvolvimento contínuo desse setor, explorando aspectos regionais e implantando inovação e criatividade.

\section{REFERÊNCIAS}

A TRIBUNA. Setor de moda foi responsável por movimentar $\mathbf{R} \mathbf{1 4 0}$ bilhões, 2016. Disponível em: http://www.atribuna.com.br/noticias/noticiasdetalhe/economia/setor-demoda- foi-responsavel-por-movimentar-r140bilhoes/?cHash=df9b65b4bab9ccaf1ac1d165fa307fdf. Acesso em: 09 de Outubro de 2017.

ABIHPEC SEBRAE. Caderno de tendências para 2019, 2020. Disponível em: https://abihpec.org.br/publicacao/caderno-de-tendencias-2019-2020/. Acesso em dia 31 de outubro de 2018.

AGDA MÔNICA. Os estilistas e a produção de moda,2007. Disponível em PDF. Acesso em: 08 de outubro de 2018.

https://repositorio.unesp.br/bitstream/handle/11449/106287/alario_mas_dr_arafcl.pdf ?sequenc $\mathrm{e}=1$

CARMO LILIANE. A indústria têxtil e de confecções e desenvolvimento regional: 2014. Disponível em PDF. Acesso em dia 25 de abril de 2019. 
moda: 2018. Disponível em PDF. Acesso em 10 de maio de 2019.

DALLA ARMANDO. Economia criativa no Brasil, quadro atual desafios e perspectivas. 2017. Disponível em: PDF. Acesso em 31 de outubro de 2018.

EDNÍSIO ROBERTO. A indústria de confecções na região nordeste: gargalos, Disponível em PDF. Acesso em dia 01 de março de 2019.

EDUARDA MARIA, moda cultura e identidades, 2008. Disponivel em: PDF. Acesso em; 24 de agosto de 2018.

FEBRATEX GROUP. A importância do polo têxtil do Nordeste para o Brasil. Disponível em: ttps://fcem.com.br/noticias/importancia-do-polo-textil-do-nordestepara-o-brasil. Acesso em dia 20 de fevereiro de 2019.

FERNANDO LUIZ. A indústria têxtil na região nordeste: gargalos 2008, Potencialidades e desafios. Disponível em PDF. Acesso em dia 04 de março de 2019.

FERRATY MARIA E BASSI MARIANA, diferenciação e competitividade da oferta de moda brasileira no mercado internacional, 2016. Disponível em: PDF. Acesso em 08 de agosto de 2018.

FOLHA DE SÃO PAULO. Indústria aprova venda da SPFW, mas não comércio de nome e desfiles, 2018.Disponivél em: https://www1.folha.uol.com.br/ilustrada/2018/04/industria- aprova-venda-da-spfwmas-nao-comercio-de-nome-e-desfil. Acesso em 19 de outubro de 2018.

GOUDENBERG MIRIAM, Arte de pesquisar,2008. Disponível em livro. Acesso em; 09 de agosto de 2018. http://www.uff.br/labesc/files/2012/03/A-Arte-de-PesquisarMirian- Goldenberg.pdf

HALF ROBERT. Mercado de moda é o que mais cresce no Brasil,2015.

DISPONÍVEL em: http://portal.metodista.br/rpcom/carreiras-e-tendencias/mercadode-moda- e-o-que-mais-cresce-no-brasil.Acesso em 08 de outubro de 2018.

KRATZ LUCIA. O processo criativo para o designer de moda, 2016. Disponível em: PDF. Acesso em:08 de outubro de 2018.

LOPES RENATA. A Indústria Têxtil no Brasil: uma perspectiva histórica e cultural: 2015. Disponível em PDF. Acesso em dia 06 de abril de 2019.

METRÓPOLES . 5 sites especializados em antecipar tendências de moda e lifestyle. ,2017. Disponível em: <<https://www.metropoles.com/colunas-blogs/sarah-gomes/5sites- especializados-em-antecipar-tendencias-de-moda-e>>.Acesso em 31 de outubro de 2018.

MINAS TREND. Moda e negócios em um evento único, 2018. Disponível em: http://www.minastrend.com.br/.Acesso em 19 de outubro de 2018. 
MORELLI-MENDES, C; DOMINGOS DE ALMEIDA, C. O desenvolvimento da economia criativa no Brasil: uma perspectiva através da indústria cinematográfica brasileira, Disponível em: PDF. 2016. Acesso em: 21 de agosto de 2017.

MUNIZ MARIA. O Ceará e a indústria têxtil no espaço-tempo: 2016. Disponível em PDF. Acesso em dia 10 de abril de 2019.

OLIVEIRA BRUNO. O setor de moda brasileiro: caso do instituto rio moda, 2017. Disponível em: PDF. Acesso em 19 de outubro de 2018.

SANTOS, H. H. O. Moda e Economia Criativa: agenciamentos em torno da produção de vestuário no Brasil. Disponível em:

http://www1.sp.senac.br/hotsites/blogs/revistaiara/wp-content/uploads/2016/09/123laraartigo.pdf. Acesso em: 16 de Setembro de 2017.

SISTEMA FIRJAN. Mapeamento da Indústria Criativa no Brasil. Disponível em: http://www.firjan.com.br/EconomiaCriativa/pages/default.aspx. Acesso em: 04 de Outubro de 2017.

TATIANA EGEL. Métodos de pesquisa,2009. Disponível em PDF. Acesso em dia 08 de outubro de 2018.

VIDA E CARREIRA. Economia Criativa, o que é isso. Disponível em:http://www.vidaecarreira.com.br/carreira-executiva/economia-criativa-o-que-eisso/ Acesso em 08 de outubro de 2018. 